\title{
Preliminary report on landslide early warning on August 20, 2021,in Nangqian County, Qinghai Province, China
}

\section{Xiangpeng Wang}

Chengdu University of Technology

Fanqiang Lin ( $\square$ linfq@cdut.edu.cn )

Chengdu University of Technology

\section{Di Shen}

Chengdu University of Technology

\section{Zhiyong Sun}

Chengdu University of Technology

\section{Research Article}

Keywords: alpine mountainous area, landslide disaster, surface deformation, monitoring and warning, threshold value

Posted Date: November 23rd, 2021

DOI: https://doi.org/10.21203/rs.3.rs-1053067/v1

License: (c) (i) This work is licensed under a Creative Commons Attribution 4.0 International License. Read Full License 


\title{
Preliminary report on landslide early warning on August 20, 2021, in Nangqian County, Qinghai Province, China
}

\author{
Xiangpeng Wang ${ }^{1}$, Fanqiang Lin ${ }^{1, *}$, Di Shen ${ }^{1}$, and Zhiyong Sun ${ }^{2}$ \\ ${ }^{1}$ Chengdu University of Technology, Chengdu,610059,Sichuan,China \\ ${ }^{2}$ Qinghai China Coal Geological Engineering Co., Ltd \\ *Wxplantian@163.com \\ +these authors contributed equally to this work
}

\begin{abstract}
Abstract: Based on the analysis of its formation mechanism, stability state and development trend, this paper focuses on monitoring key indicators such as surface deformation and rainfall to realize early warning of landslide and provide some guidance for landslide disaster prevention and avoidance in the alpine mountainous area of Nangqian, Qinghai Province. The landslide of the Baima Elin Monetary has the topographic and geomorphological conditions of landslide formation, and has the basic characteristics of being influenced by rainfall and climate, so the warning of the landslide should be comprehensive. At the same time, the current situation of the landslide is in an unstable state, and the seasonal freeze-thaw cycle will cause its stability to weaken further. Through macroscopic signs, it is predicted that the deformation of Baima Elin Monetary landslide will continue to intensify without a sign of abatement, and the stability will be further reduced after winter, tending to develop in an unfavorable direction, and engineering measures should be taken as soon as possible to manage it.

Keywords: alpine mountainous area; landslide disaster;surface deformation; monitoring and warning; threshold value.
\end{abstract}

\section{Introduction}

Nangqian is located in the Southeastern Tibet Plateau,stretching a vast area from the south of Kunlun Mountains to the north of Tanggula Mountains. The county is the southern gate of Qinghai Province, and also a major pastoral region. Within the region, the terrain is of a high altitude, with gaping deep valleys and everlasting tall mountains. Since August 10th, 2021, a rise of the rainfall has been witnessed in the Baima Elin Monastery area of the Jiqu Township, Nangqian County in Yushu of the Qinghai Province. (Geological location: Longitude $96^{\circ} 1451.00$, latitude $32^{\circ} 0042.12$ )As is shown in the Fig. 1 . On August 19th, the rainfall per hour reached $8 \mathrm{~mm}$, with a total of $100 \mathrm{~mm}$ for the day. In addition, a geological disaster early warning has been given at 4 AM on August 20th.

The landslide reached $25 \mathrm{~m} 3$, causing different scales of damages to the monk's retreat and the wall of the Great Hall but without direct economic losses and casualties. The panorama of the landslide is shown in the Fig.2. After the landslide, at 11:00 AM on August 20, 2021, technicians of the Qinghai Coal Geo-engineering Co. LTD Arrived the site and investigated the landslide. The landslide is about $35 \mathrm{~m}$ long, $85 \mathrm{~m}$ wide, $4 \mathrm{~m}$ thick, $1.2 \times 104 \mathrm{~m} 3$ in scale and $5.2 \times 104 \mathrm{~m} 3$ in volume. At present, the landslide's back edge pulling crack tends to widen and deepen, under the effect of heavy rainfall and earthquake, there may be local landslides or collapse disaster, which poses a threat to the monastery.

\section{Geological and morphological setting}

The landslide is located on the northern slope of the Shanrong Village, Jiqu Township of the Nangqian County. It is in the front edge of a low mountain in an erosion structure, and the slope is generally 25-35 degrees, with a relative height difference of 90m. The rock nature of the original slope in the survey area is the Neogene mud rock, which has a rock formation mechanism. The rock quality is very soft and weak in expansion, easy to soften and disintegrate when reacting with water, and has a poor weather resistance (BAI et al. 2021; Wang et al. 2020; Du.2020). The rock surface of the exposed formation in the landslide area is the broken gravel of the Quaternary (He et al. 2020; Xin et al. 2018). The lithology is yellow-brown conglomerate, gray-purple conglomerate, medium-fine-grained quartz sandstone, quartz siltstone, purple-red mudstone, and gray-white gypsumstone, the stratigraphic section is shown in Fig. 3 (Zhang et al.2013). The back edge of the landslide is located on the south side of sinking steep bump under the landslide, which is a potential landslip area, with an elevation of 3658 to $3670 \mathrm{~m}$. The slope is 


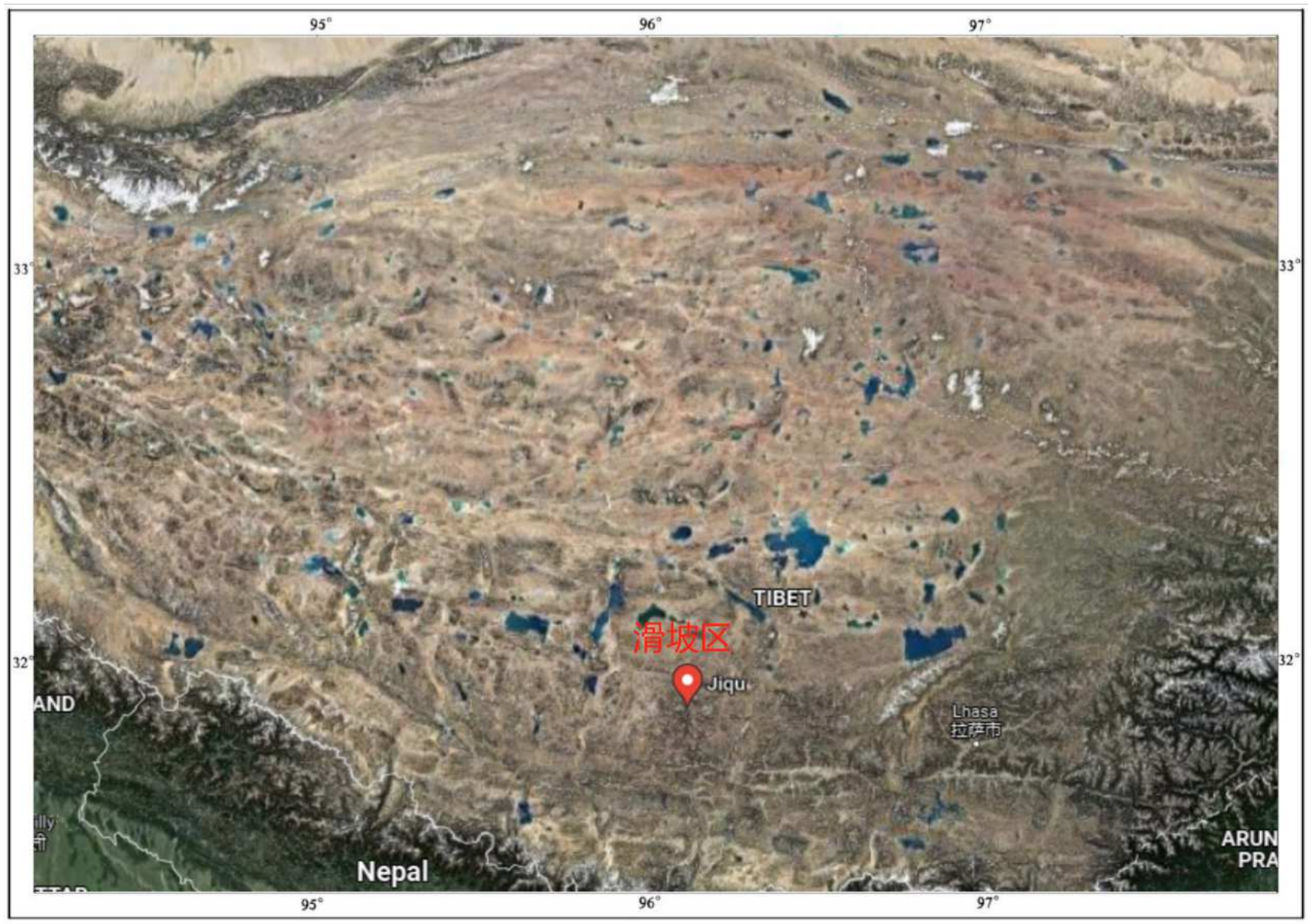

Figure 1. Geological graph of the Landslide.

rather complete, and no obvious signs of deformation are found, with an average slope of 22 degrees. The top of the slope is covered by gravels, and gravel grinding roundness is angular-based, with the particle size ranging from 0.1 to $0.5 \mathrm{~m}$. From the top of the slope to the wrong steep place, vegetation coverage gradually increased, between $15 \%$ to $55 \%$.

The survey information indicates that mixed-structure powder clay is distributed on the landslide slop in the survey area, the thickness of the layer is uneven, the structure is messy, including gravel and mud rock blocks, and the mechanics are poor (Wei et al. 2021). The miscellaneous fill is mainly distributed at the foot of the landslide slope in the survey area, and is formed by artificial excavation of the foot of the slope to build the urban underground draining system and level ground, mainly concrete, brick, plastics, waste batteries and other construction waste. The soil is slightly wet, of a loose structure and poor mechanics.

\section{Characteristics of the landslide}

After on-site investigations, the landslide turns out a small moving earthen landslide, with the trailing edge elevation of $3704 \mathrm{~m}$, leading edge elevation of $3683 \mathrm{~m}$, landslide height of $21 \mathrm{~m}$, slope of 45 degrees, and landslide sliding direction of 155 degrees. The Landslide is in the stage of peristaltic deformation, after field inquiries and investigation, knowing the landslide's pull cracks formed in two periods of time, which are directly related to rainfall. The first time in the mid-July 2015, mainly in the north side of the landslide's back edge formed two tensile cracks, which are about 3-5m, with the crack width of 0.2-0.3m, underneath $0.3 \mathrm{~m}$, the maximum observed depth of $0.5 \mathrm{~m}$. It is a semi-circular distribution, as is shown in Fig 4;

The second landslide happened at 4 AM, August 20th,2021.10 tensile cracks were formed on the upper slope, and their length ranges from 2 to $8 \mathrm{~m}$, width from 0.15 to $0.5 \mathrm{~m}$, the whole sinking $1-3 \mathrm{~m}$, and visible depth from 0.5 to $1.5 \mathrm{~m}$. The cracks stretched through the east-west orientation. as is shown in Fig 4. 


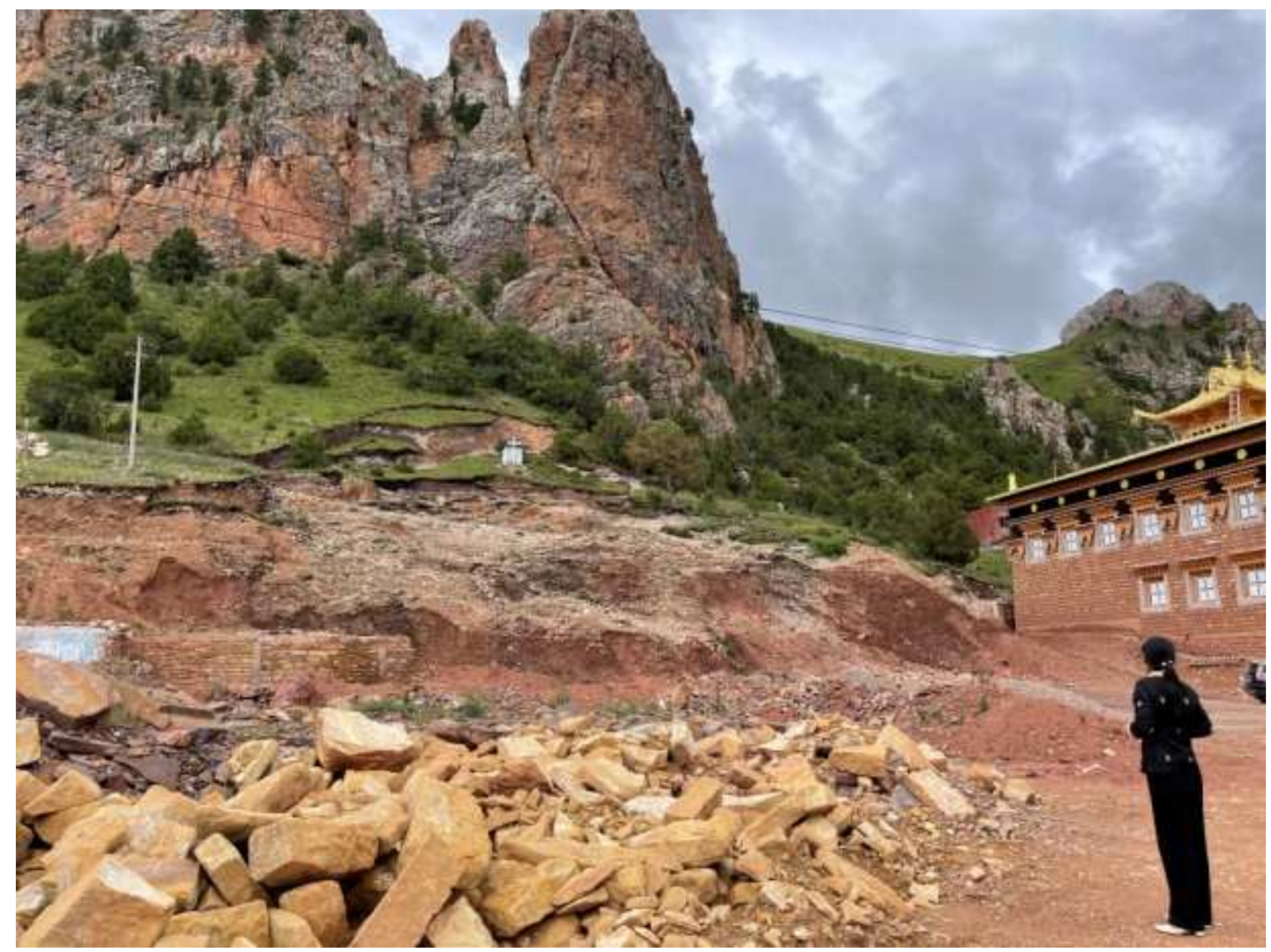

Figure 2. The panorama of the landslide.

\section{Process monitoring}

For the prevention of landslide geological disasters, the local government jointly undertook the prevention research by the State Key Laboratory of Geohazard Prevention and Geoenvironment Protection (Chengdu University of Technology) and Qinghai China Coal Geological Engineering Co., Ltd. in January 2021. This disaster point, 4 earth movement monitors, 1 GNSS base, 2 fissure meters, and 1 rain gauge are as settled according to the Fig 5, and the geological disaster 2-2 survey line profile is shown in the Fig 6.

\section{The development and Forecast}

The Rain gauge data of the Baima Elin Monetary of Jiqu Township shows from August 10th the data of the rain gauge is increasing, and the rainfall reaches $8 \mathrm{~mm}$ per hour on August 19th, with the accumulated rainfall about 100mm(The rainfall capacity is shown in the Fig.7).The continuous heavy rainfall made rain sinking into the loose layer and existing cracks, increasing the weight of the slope and lowering the shear strength, which is the direct cause of landslide(He et al. 2020; Xin et al. 2018). At 4AM, August 20th, in the Baima Elin Monetary, Jiqu Township in Nangqian County in Yushu of Qinghai Province, the 02GP01(Surface displacement meter) triggered the single parameter warning, the 11GP01(Surface displacement meter) was of orange alert (Surface movement data is shown in the Fig 8), and the landslide observation system triggered an orange alert, which means that the slope is in the stage of accelerated deformation, and the probability of landslide is very high in a few days. 


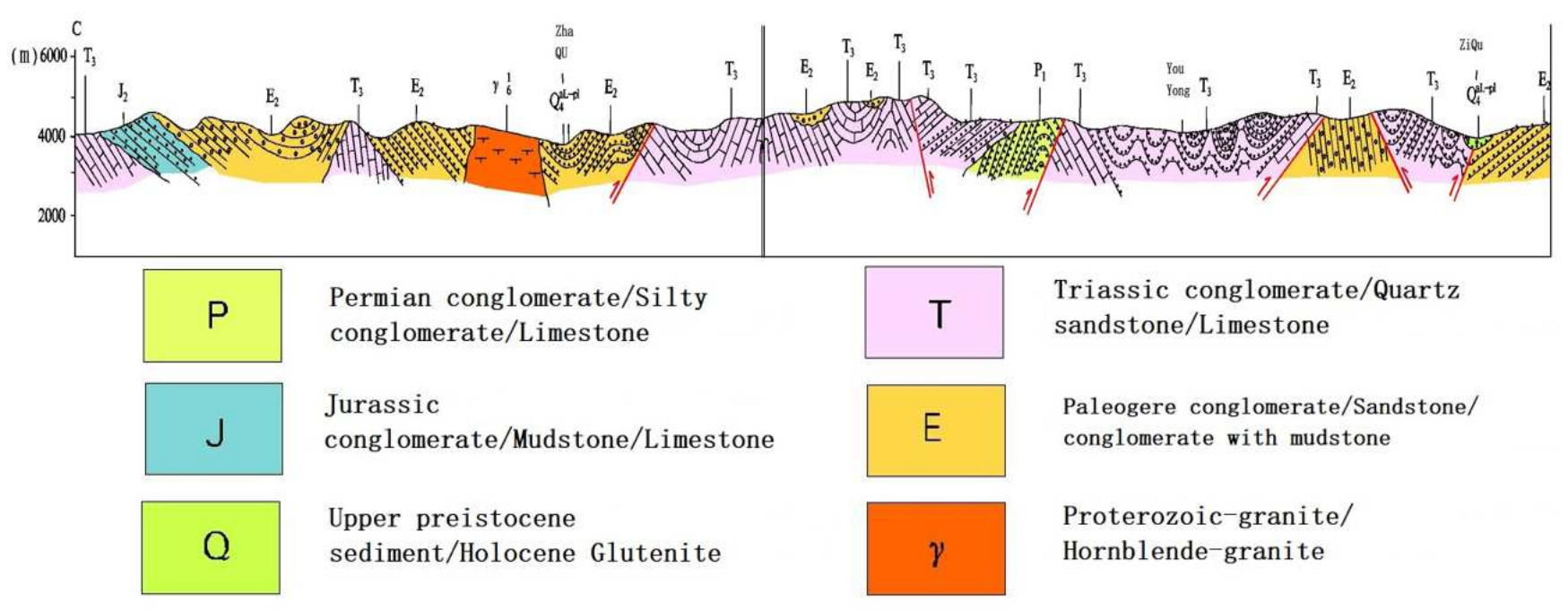

Figure 3. Geological profile. (Figure 3 quoted from 7 refs, <China Geological Survey, Ministry of land and resources. Detailed investigation of geological hazards in Qinghai>)

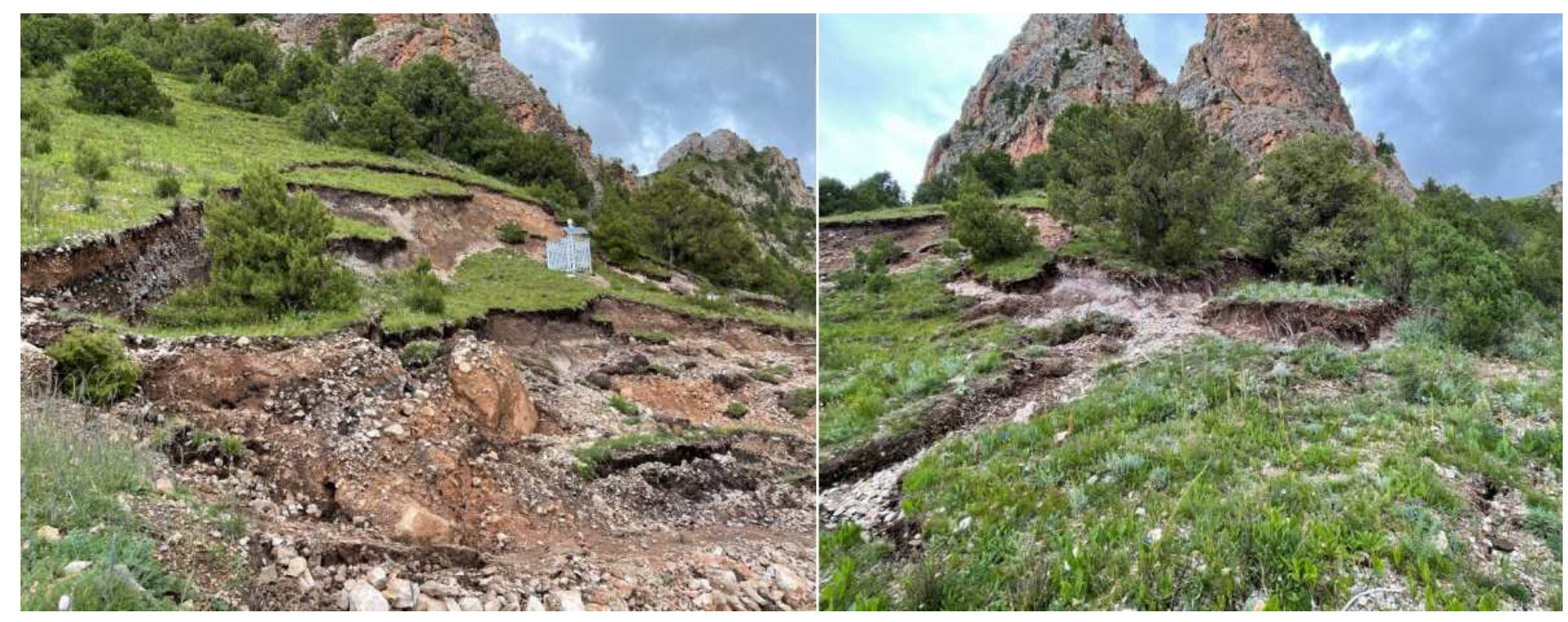

Figure 4. Tensile cracks of Trailing edge (2015.07) and Landslide tensile cracks (2021.08).

\section{Conclusion}

The landslip in the Baima Elin Monetary of Jiqu Township was mainly under the effect of the continuous heavy rainfall and favorable landform, formation lithology and regional structural conditions. The infiltration of rain lowered the shear strength of the earth on the slope and increased the weight of the rock formation, which increased the sliding power and coefficient of stability of the side slope. All of them resulted in the landslip. The successful early warning effectively guaranteed the life safety of Temple monks and reduced economic losses.

\section{Methods}

Topical subheadings are allowed. Authors must ensure that their Methods section includes adequate experimental and characterization data necessary for others in the field to reproduce their work. 


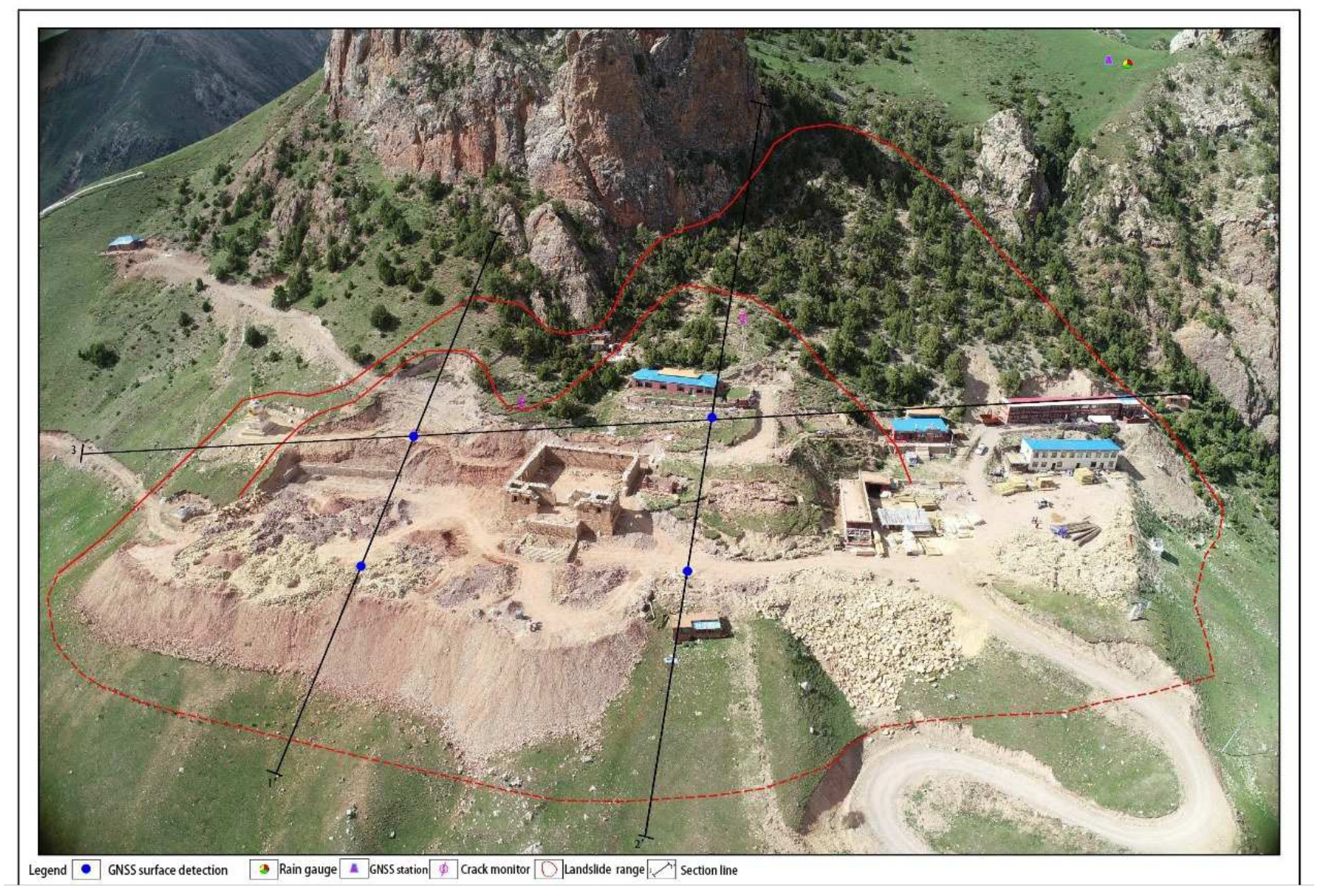

Figure 5. Landslip monitoring setup elevation.

\section{References}

1. Bai C, Peng L, Shen Y, et al (2021) Characteristics and Mechanism of Zhangjiawan Large Scale Landslide in Xining. Science Technology and Engineering 21:927-934.

2. He K, Liu B, Hu X (2021) Preliminary reports of a catastrophic landslide occurred on August 21, 2020, in Hanyuan County, Sichuan Province, China. Landslides 18:503-507.

3. Wei Z, Zhang J, Cao X, et al (2021) Causes and influential factor analysis of landslides and rockfalls in northsouth mountain areas of Xining City, Qinghai Province. The Chinese Journal of Geological Hazard and Control 32:47-55

4. Du W (2020) Study on the development characteristics and genesis mechanism of geological disasters in Xiaqiongsi scenic area,Hualong County,Qinghai Province. Journal of Northwest Normal University(Natural Science) 56:129-134

5. Wang Z, Zhao F, Xie W, et al (2020) Formation Condition Analysis and Stability Evaluation of Gaojiawan Landslide in Qinghai Province. Bulletin of Soil and Water Conservation 40:81-87

6. Xin P, Wang T, Wu S (2018) A Study of the Formation Mechanism of Caizigou Large-scale Translational Gliding Landslide in Neogene Mudstone Basin of Xining-Minhe, Qinghai Province. Acta Geoscientica Sinica 39:342-350.

7. Maosheng Zhang, Weidong Shi, Changyun Zheng, et al(2013) Detailed investigation report on geological hazards in Yushu prefecture. Qinghai province (Nangqian Country).The Assignment No:1212011140142 


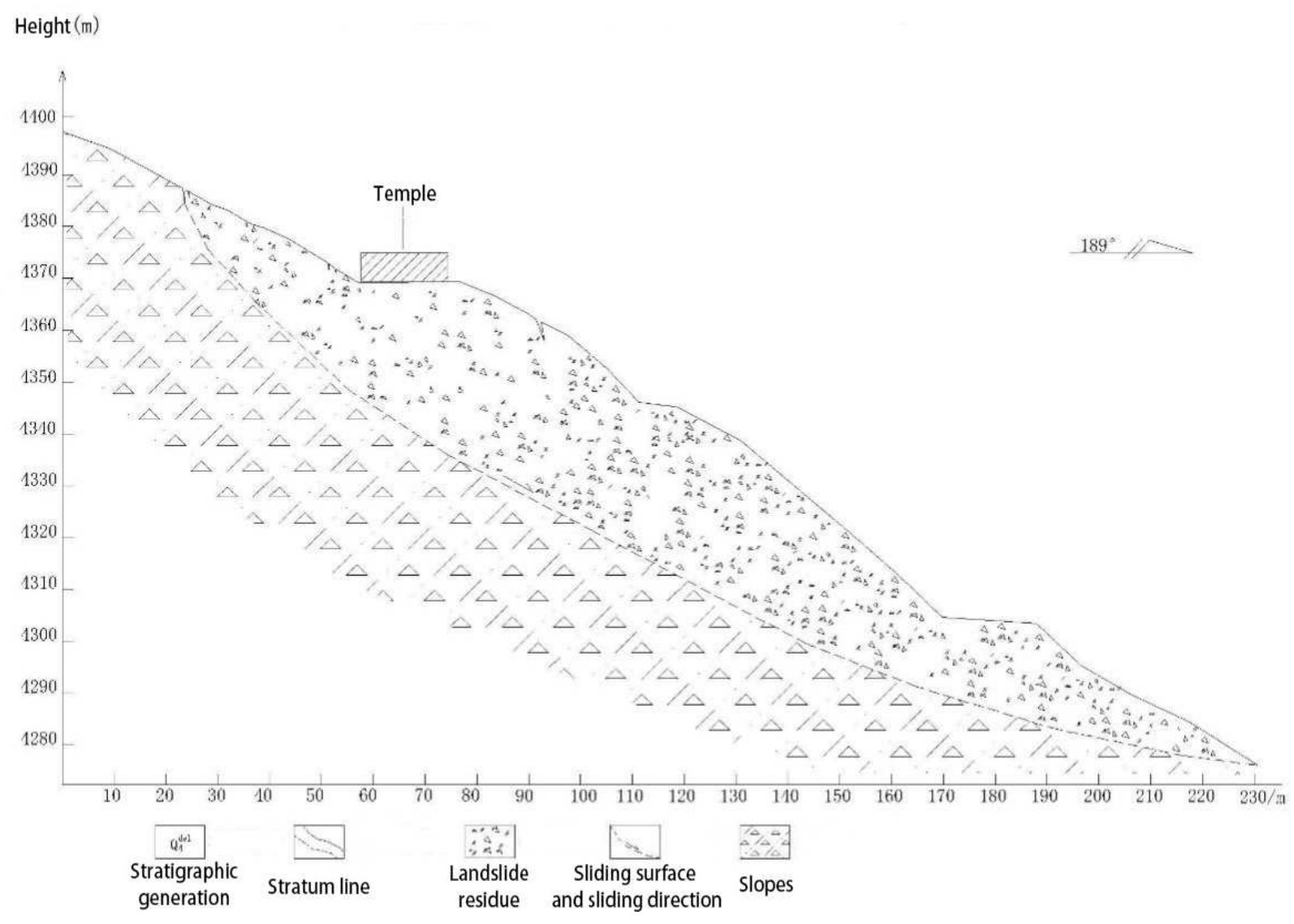

Figure 6. Geological disaster 2-2 profile.

\section{Acknowledgements}

We are truly grateful for the capital support of the National Natural Science Foundation of China (Grant No. 41930112 and Grant No. 41977252).

\section{Author contributions statement}

All authors contributed equally to the manuscript. All authors read and approved the final manuscript.

\section{Competing interests}

The authors declare no competing interests. 


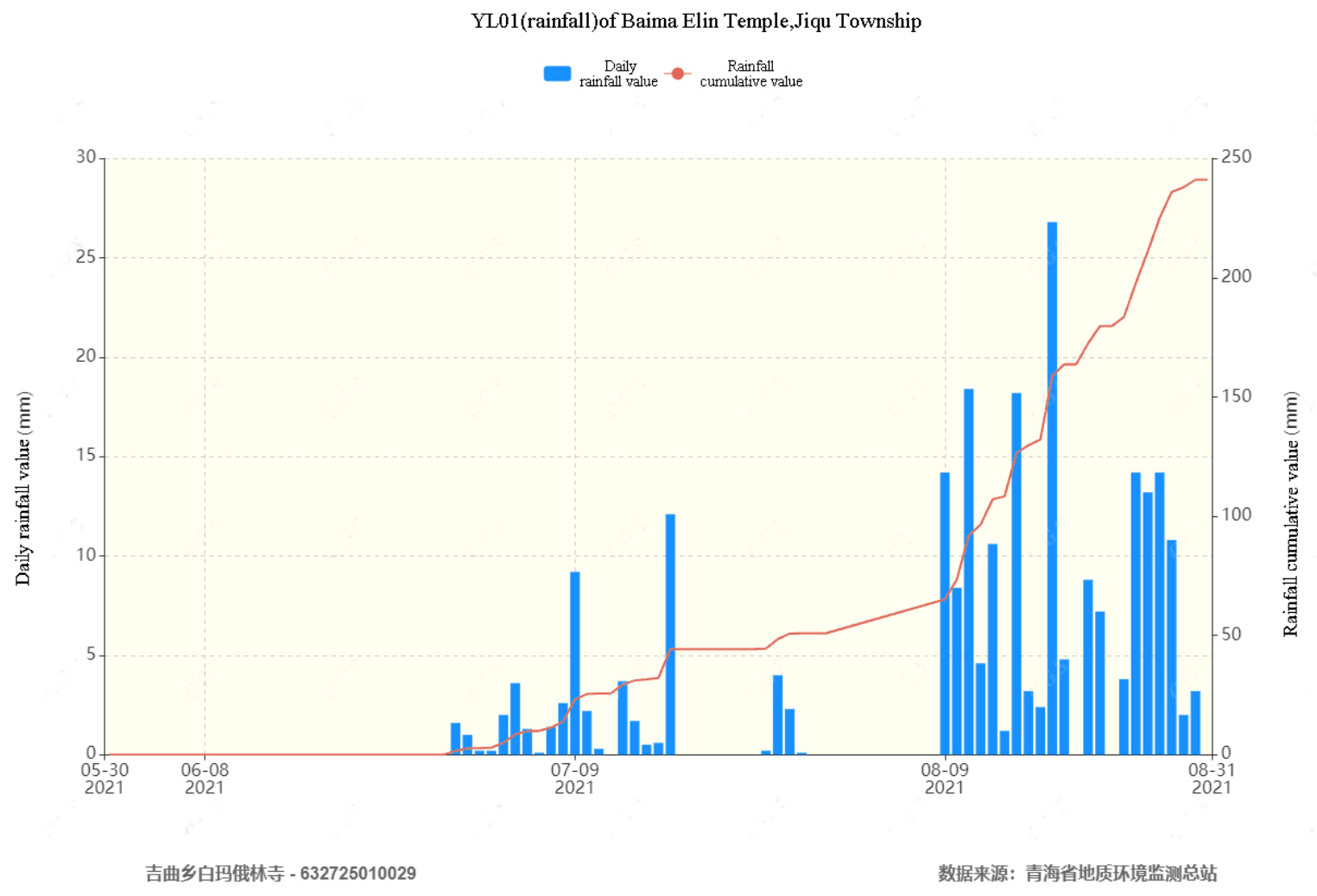

Figure 7. Rainfall on a single day and accumulated rainfall from May 31st to August 31st,2021.

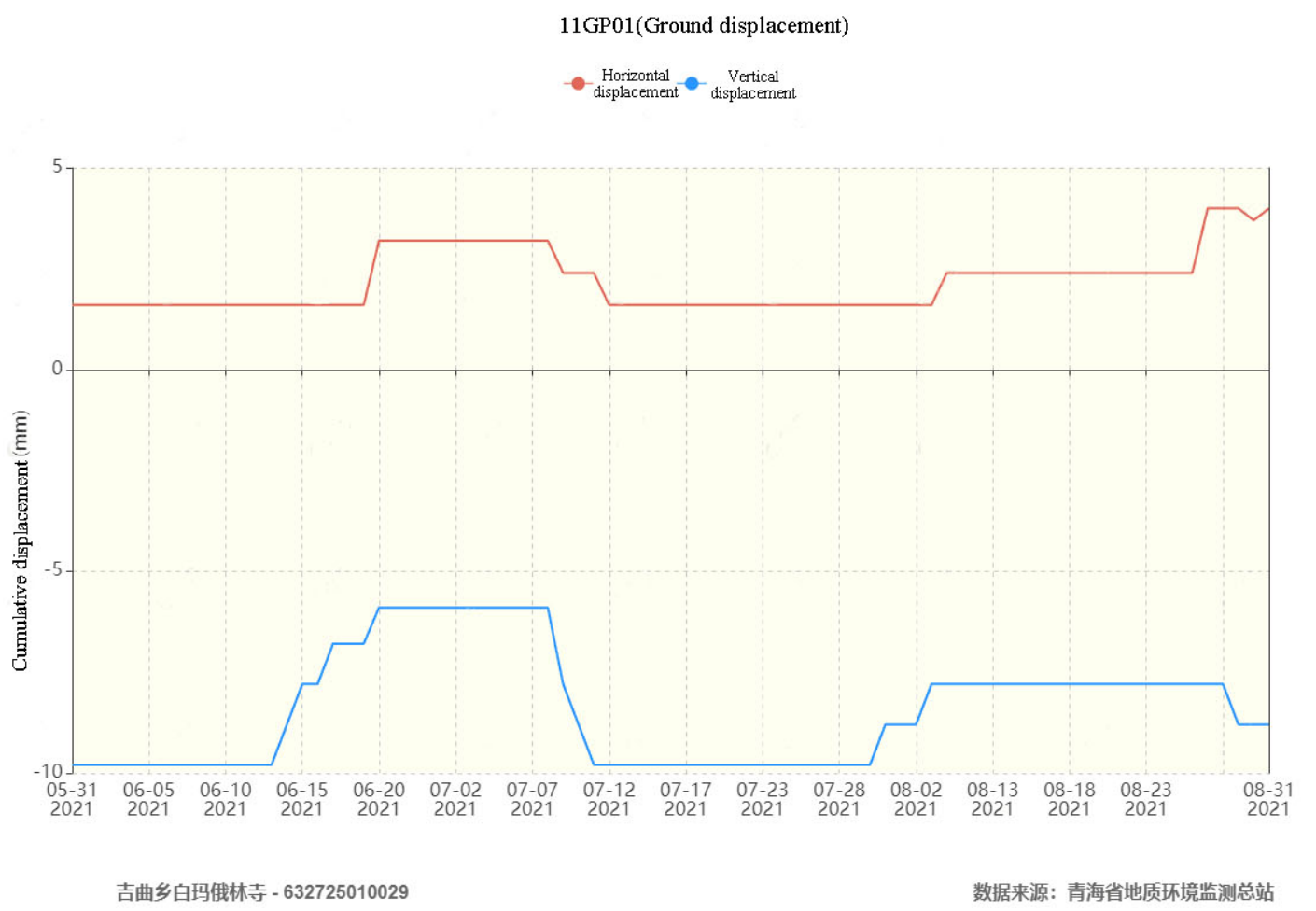

Figure 8. Horizontal and vertical accumulated movement from May 31st to August 31st, 2021. 